\title{
Large calcified renal artery aneurysm in the renal sinus misdiagnosed as an intrapelvic calculus followed by mistakenly performed PCNL: a case report
}

\author{
Chao Chen ${ }^{1}$, Xuliang Wang ${ }^{1}$, Fang Xin ${ }^{1}$, Lugeng He${ }^{1}$, Kang Jiang ${ }^{1}$, Jia Shao ${ }^{1}$ and Liping Xie ${ }^{2^{*}}$ (D)
}

\begin{abstract}
Background: Renal artery aneurysms (RAAs) are rare and usually asymptomatic, and some RAAs can be associated with calcifications, which may lead to misdiagnoses as renal calculi, which are then mistakenly treated.

Case presentation: A 69-year-old female patient was admitted to the hospital with no discomfort and was diagnosed with a large right renal calculus. The ultrasound and computed tomography urography (CTU) scan suggested a large calculus in the right pelvis with hydrops of the kidney. Therefore, we chose percutaneous nephrolithotomy (PCNL) to treat the right renal calculus, but no calculi were found in the renal pelvis. When we removed the mucosa of the renal pelvis with a holmium laser, we observed a fluctuating unruptured aneurysm with calcification. Therefore, the previous diagnosis of a renal calculus was disregarded. The operation was stopped immediately, and then computed tomography $(C T)$ angiography was performed, confirming the right renal aneurysm with calcification. Then, Renal artery aneurysm (RAA) coil embolization was performed. After a long-term follow-up, the patient recovered well.

Conclusions: The RAA of this patient had calcific changes, which led us to errors in the diagnosis. Hence, it is very important for surgeons to effectively distinguish between renal calculi and aneurysms with ring-like calcifications. Our case report looks back at the thrilling situation during the operation and advises surgeons on how to deal with this situation properly.
\end{abstract}

Keywords: Renal calculus, Renal artery aneurysm, Percutaneous nephrolithotomy, Embolization

\section{Background}

Renal artery aneurysms (RAAs) are uncommon and usually asymptomatic, but some demonstrate clinical symptoms such as hypertension, abdominal pain, and haematuria and have a risk for rupture [1-3]. RAAs can be associated with calcifications, which may lead to misdiagnoses as renal calculi. We report a patient with a

\footnotetext{
* Correspondence: xielp@zju.edu.cn

${ }^{2}$ Department of Urology, The First Affiliated Hospital, Zhejiang University School of Medicine, Hangzhou, China

Full list of author information is available at the end of the article
}

right calcified RAA misdiagnosed with a renal calculus who mistakenly underwent percutaneous nephrolithotomy (PCNL).

\section{Case presentation}

A 69-year-old female patient who had a history of renal calculi and diabetes mellitus was admitted to the hospital because of a large right renal calculus found by urinary ultrasonographic examination.

The patient had no discomfort, and no positive signs were found on physical examination. The 
ultrasound showed that there was a large calculus in the right renal pelvis and multiple calculi in the left kidney, and both kidneys had hydronephrosis. The kidney-ureter-bladder radiograph (KUB) appearance supported the ultrasonographic findings. However, the core of the right renal calculus appeared to be radiolucent on plain films. The computed tomography urography (CTU) scan also suggested a calculus in the right pelvis with hydrops in the upper calyx of the kidney and left renal calculi with hydronephrosis (Fig. 1). However, when we analysed the CTU images for the second time, we found that there was a low-density lesion in the calculus on the non-contrast-enhanced CTU sequence, which we thought was a foreign body or infection, so empirical anti-infection therapy was provided.

Then, PCNL was performed on the patient's right renal pelvis calculus. We chose the posterior lower renal calyces for puncture and established the operation channel. No calculi were found in the renal pelvis or any calyces, but we could feel the calculus with the forceps under the mucosa of the renal pelvis, so we considered the calculus to be located in the diverticulum. Then, we removed the mucosa of the renal pelvis with a holmium laser until the calculus was observed. When cutting the surface of the calculus with a holmium laser, we observed a fluctuating unruptured aneurysm (Fig. 2). Therefore, the previous diagnosis of a renal calculus was disregarded, and a calcified renal artery aneurysm was considered.
The operation was stopped immediately, and the patient was transferred to the endovascular treatment department. The haemoglobin re-examination results were normal after PCNL; then, computed tomography (CT) angiography was performed, confirming the right renal aneurysm with calcification (Fig. 3). RAA coil embolization was performed under local anaesthesia on the 9th day after PCNL (Fig. 4).

After more than 1 year of follow-up, the patient recovered well.

\section{Discussion and conclusions}

RAAs are defined as focal, isolated dilatations of all three layers of the arterial wall that measure $>1.5$ times the diameter of the adjacent disease-free proximal arterial segment [4]. The estimated incidence of RAAs is very low, approximately $0.09 \%$ in the general population, but it may be as high as approximately $2.5 \%$ in the hypertensive population [5]. In recent years, with the increasing use of ultrasonography, CT, magnetic resonance imaging (MRI), and digital subtraction angiography (DSA) to image the renal artery, asymptomatic RAAs have been widely recognized and treated [6]. RAAs are usually asymptomatic, but symptomatic patients can have difficult-to-control hypertension, haematuria, and abdominal pain. A total of $56 \%$ of RAAs have calcific changes [7], so it is very important for us to effectively distinguish between renal calculi and aneurysms with ring-like calcifications.
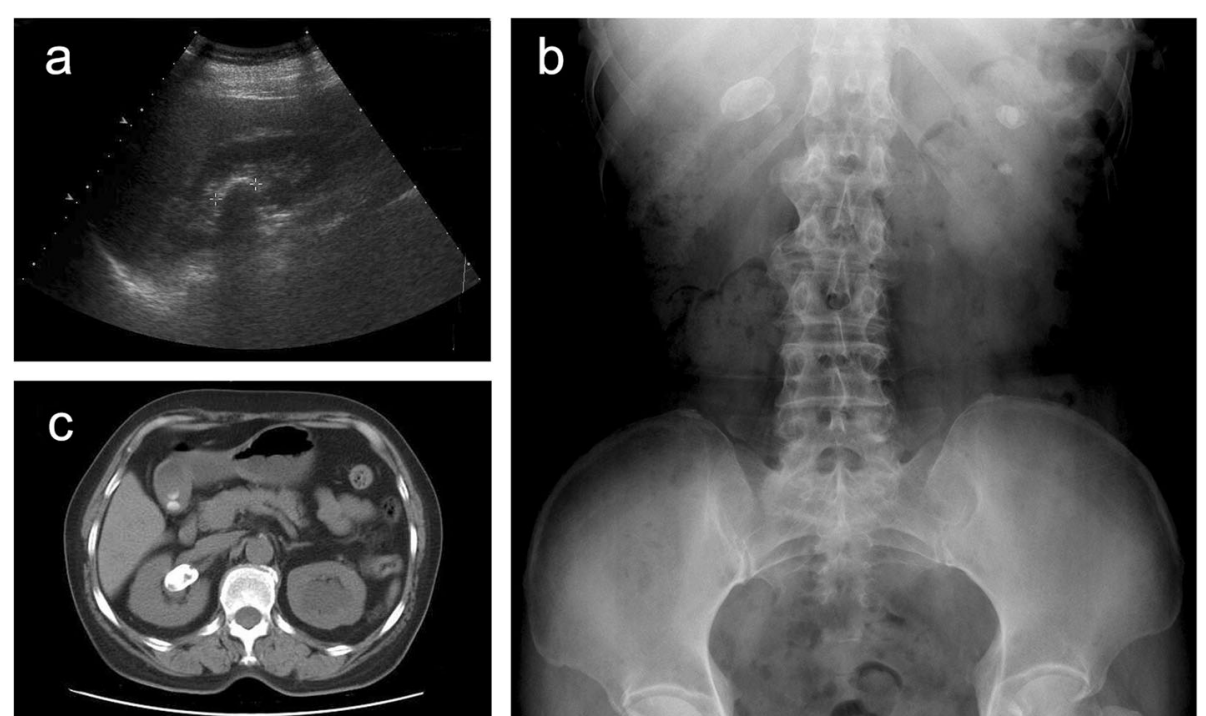

Fig. 1 a Urinary ultrasonographic examination shows a hyperechoic focus in the right renal pelvis with an acoustic shadow. b KUB shows a large calculus in the right kidney and multiple calculi in the left kidney. c The non-contrast-enhanced CT image selected from the plain scan CTU sequence shows a calculus with a density of $508 \mathrm{HU}$ and a size of $3 \times 2.3 \mathrm{~cm}$, with low-density lesions located in the right pelvis 


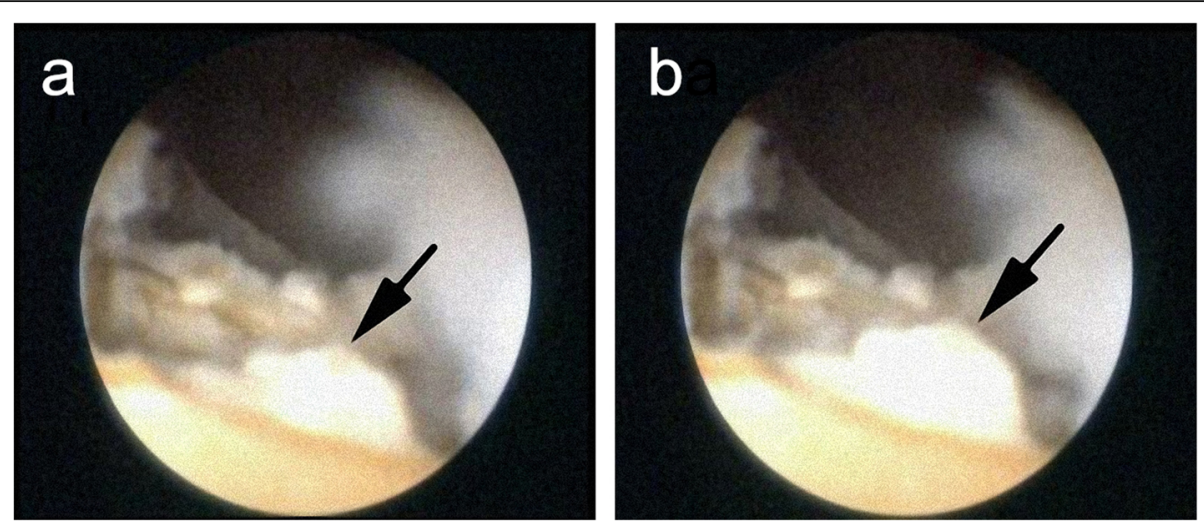

Fig. 2 Images from a screenshot of the video show two different states of aneurysm pulsation (arrow). a The image shows the constricted state of aneurysm. $\mathbf{b}$ The image shows the expanded state of aneurysm

Catheter-based arteriography is the gold standard for the diagnosis of RAAs, although CT is the most common contemporary non-invasive diagnostic modality, followed by MRI and ultrasonography. When an RAA is complicated by calcifications, it may be misdiagnosed as a renal calculus, especially if the calcified vessel wall of the renal arterial branch passes through the sinus [8]. In our case, both the ultrasound and CTU findings showed a calculus in the right pelvis. Although we found low-density lesions in the calculus on CT, we did not consider the rare occurrence of a calcified RAA. This is why PCNL was mistakenly performed. Fortunately, we followed the two principles of PCNL surgery and avoided directly rupturing the aneurysm. First, in the process of making the channel, we followed the direction of the target renal papilla for the puncture, rather than targeting the calculus. Second, in the process of lithotripsy, the surface of the stone was treated first, and the core was not always targeted. This case reminds us that if there are abnormal lesions in the renal calculus, the possibility of an aneurysm should be taken into account, and CT angiography, catheter angiography, or other examinations need to be completed for further diagnosis.

Currently, the accepted indications for RAA intervention include a size $>2 \mathrm{~cm}$, female patients of childbearing age, ruptured RAAs, and symptoms, such as pain, haematuria, and medically refractory hypertension [9]. Surgical resection and endovascular repair are the main contemporary management strategies for RAAs. With the development of endovascular techniques and improvements in perioperative management, Cochennec $F$ et al. [10] argues that endovascular treatment is a valid alternative to open repair, but patients are exposed to the risk of
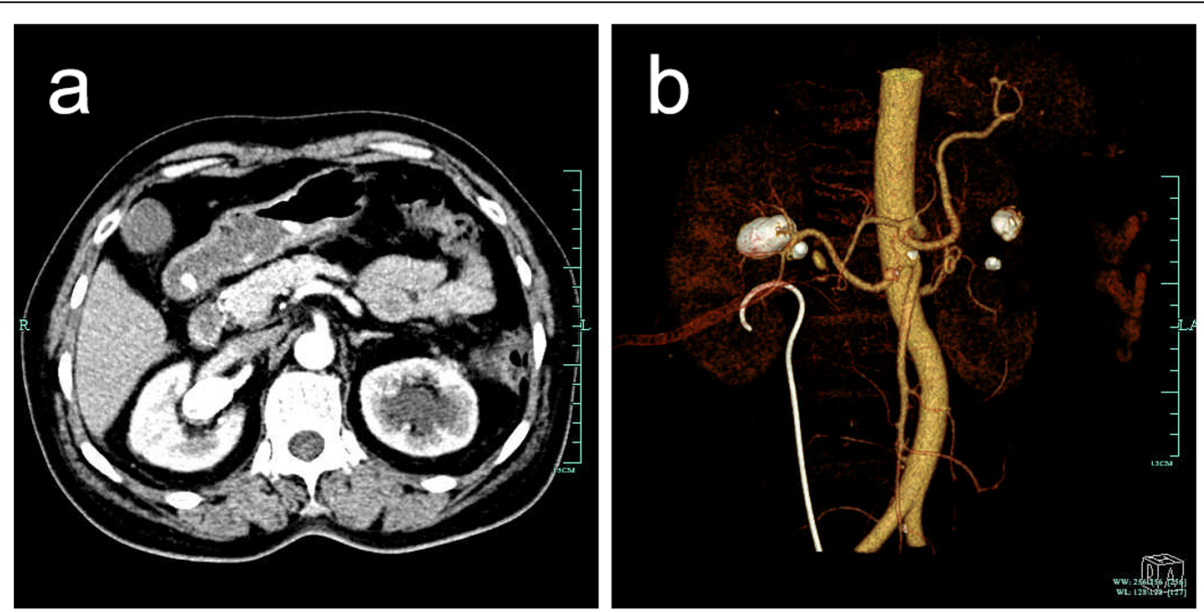

Fig. 3 a The contrast-enhanced CT scan shows the right renal arterial branch penetrating into the aneurysm. $\mathbf{b}$ The coronal image and 3dimensional reconstruction show multiple aneurysms in both kidneys. The large right RAA was located at the first bifurcation of the renal artery 

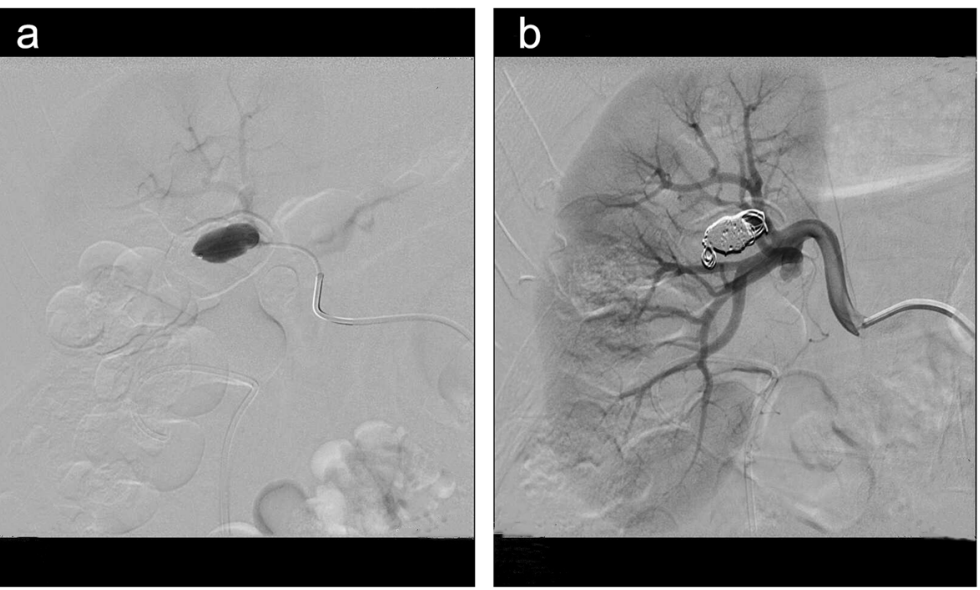

Fig. 4 a Angiography image shows the right RAA. b Angiography image shows that the right RAA was treated with coil embolisation

aneurysmal reperfusion. Therefore, the authors advise that endovascular repair should be considered as an elective first-line treatment for older patients, especially those with ruptured RAAs. We chose endovascular repair for our elderly patient in this case after a multidisciplinary team (MDT) meeting. The reasons were as follows. First, the size of the aneurysm was greater than $2 \mathrm{~cm}$, although the patient had no symptoms. Second, the calcified shell of the aneurysm had been destroyed, and we considered that the wall of the aneurysm may be corroded by urine, which would increase the risk of aneurysm rupture. To date, no complications have occurred, including aneurysmal reperfusion.

The main reason that we performed the wrong treatment was that we made a misdiagnosis before the operation. We ignored the patient's unusual CT and KUB imaging findings before PCNL. We report this case in order to avoid the recurrence of similar mistakes in the future and to learn something from this mistake. Our case suggests that for patients who are considered to have renal calculi clinically, we need to pay more attention to the patients' CTU appearance, KUB presence, Doppler ultrasound imaging results, clinical symptoms and signs, histories of basic diseases such as hypertension, etc. We need to rule out the possibility of aneurysms associated with calcification if there are conditions such as an abnormal CT appearance, especially if low-density lesions are observed in the centre of the stone, if there are stones located in the path of the renal artery or its branches, if KUB shows ringlike calcifications in the region of the kidney, if Doppler ultrasound shows strong echo lesions around the renal sinus, if there is a lack of typical clinical symptoms and signs of urolithiasis, if there is a history of hypertension that is difficult to control, etc. We also need to pay attention to the patient's sex and age group, as aneurysms are more common in older women [7]. Therefore, we strongly propose that $\mathrm{CT}$ angiography should be performed before considering surgical options for such renal calculi.

There are very few reported cases of RAAs misdiagnosed as renal calculi (Table. 1). To the best of our knowledge, unlike previously reported cases, this is the first reported case of a pulsating aneurysm that was observed during PCNL surgery. The case report looks back at the intense situation during surgery and advises surgeons on how to deal with this situation properly.

Table 1 Reported cases of RAAs misdiagnosed as renal calculi

\begin{tabular}{|c|c|c|c|c|c|c|c|c|c|c|}
\hline Reference & Year & Age & Gender & Presentation & Misdiagnosis & Size $(\mathrm{cm})$ & Hydro-nephrosis & Mis-treatment & Final treatment & $\begin{array}{l}\text { Recurrence/ } \\
\text { Follow-up time }\end{array}$ \\
\hline $\begin{array}{l}\text { Chen SW } \\
\text { et al. [8] }\end{array}$ & 2013 & 51 & Woman & $\begin{array}{l}\text { Left } \\
\text { lumbago }\end{array}$ & $\begin{array}{l}\text { Left intrapelvic } \\
\text { calculus }\end{array}$ & 2.5 & Yes & ESWL & Left nephrectomy & None/18 months \\
\hline $\begin{array}{l}\text { Sallami S } \\
\text { et al. [11] }\end{array}$ & 2014 & 42 & Woman & $\begin{array}{l}\text { Right-sided } \\
\text { lumbar pain }\end{array}$ & $\begin{array}{l}\text { Right intrapelvic } \\
\text { calculus }\end{array}$ & 1.1 & No & ESWL & Vascular treatment & NA \\
\hline
\end{tabular}

NA not available, ESWL extracorporeal shock wave lithotripsy 


\section{Abbreviations}

RAAs: Renal artery aneurysms; CTU: Computed tomography urography; PCNL: Percutaneous nephrolithotomy; CT: Computed tomography; KUB: Kidney-ureter-bladder radiograph; MRI: Magnetic resonance imaging; DSA: Digital subtraction angiography; MDT: Multidisciplinary team

\section{Acknowledgements}

The authors thank the patient for allowing us to publish this case report. And we would like to thank American Journal Experts for providing linguistic assistance during the preparation of this manuscript.

\section{Authors' contributions}

CC and XLW performed PCNL; FX and JS performed endovascular treatment; LGH collected the clinical data and compared the current case with the literature; KJ collected images and clipped the video; CC wrote the manuscript. LPX critically revised the manuscript. All authors read and approved the final manuscript.

\section{Funding}

We are thankful for the financial support from Zhejiang Natural Science Foundation Committee Project (Y18H160285). They provided financial support for the manuscript revising and data collecting.

\section{Availability of data and materials}

The datasets used and/or analysed during the current study are available from the corresponding author on reasonable request.

\section{Ethics approval and consent to participate}

Not applicable.

\section{Consent for publication}

Informed consent was obtained in both written and verbal format from the. patient to publish this case report and any accompanying images.

\section{Competing interests}

The authors declare that they have no competing interests.

\section{Author details}

'Department of Urology, Affiliated Hangzhou First People's Hospital, Zhejiang University School of Medicine, Hangzhou, China. ${ }^{2}$ Department of Urology, The First Affiliated Hospital, Zhejiang University School of Medicine, Hangzhou, China.

Received: 25 March 2020 Accepted: 30 July 2020

Published online: 10 August 2020

\section{References}

1. Peterson L, Corriere MA. Treatment of renal artery aneurysms. J Cardiovasc Surg. 2015:56(4):559-65.

2. Eskandari MK, Resnick SA. Aneurysms of the renal artery. Semin Vasc Surg. 2005;18(4):202-8.

3. Marwah S, Singla S, Kalra R, Marwah N, Singh SP. Is it renal colic or ruptured dissecting aneurysm of renal artery?: a case report. Cases J. 2009:2(1):9398.

4. Hirsch AT, Haskal ZJ, Hertzer NR, Bakal CW, Creager MA, Halperin JL, et al. ACC/AHA guidelines for the management of patients with peripheral arterial disease (lower extremity, renal, mesenteric, and abdominal aortic).. Vasc Interv Radiol. 2006:17(9):1383-98.

5. Hagihara M, Kitagawa A, Izumi Y, Ohshima Y, Katsuda E, Matsuda J, et al. Emergent coil embolization for ruptured renal artery aneurysm. Jpn J Radiol. 2009;27(7):275-9

6. Gonzalez J, Esteban M, Andres G, Linares E, Martinez-Salamanca JI. Renal artery aneurysms. Curr Urol Rep. 2014;15(1):376.

7. Klausner JQ, Lawrence PF, Harlander-Locke MP, Coleman DM, Stanley JC, Fujimura N. The contemporary management of renal artery aneurysms. $J$ Vasc Surg. 2015;61(4):978-84.

8. Chen SW, Meng HZ, Cao M, Baihua S. Renal artery aneurysm mimicking renal calculus with hydronephrosis. Am J Kidney Dis. 2013;61(6):1036-40.

9. Coleman DM, Stanley JC. Renal artery aneurysms. J Vasc Surg. 2015:62(3): 779-85
10. Cochennec F, Riga CV, Allaire E, Cheshire NJW, Hamady M, Jenkin $M P$, et al. Contemporary management of splanchnic and renal artery aneurysms: results of endovascular compared with open surgery from two European vascular centers. Eur J Vasc Endovasc Surg. 2011;42(3): $340-6$.

11. Sataa S, Habiba M, Emna M. An unusual case of a calcified renal artery aneurysm mimicking a renal calculus. Tunis Méd. 2014;92(4): 287-8.

\section{Publisher's Note}

Springer Nature remains neutral with regard to jurisdictional claims in published maps and institutional affiliations.
Ready to submit your research? Choose BMC and benefit from:

- fast, convenient online submission

- thorough peer review by experienced researchers in your field

- rapid publication on acceptance

- support for research data, including large and complex data types

- gold Open Access which fosters wider collaboration and increased citations

- maximum visibility for your research: over $100 \mathrm{M}$ website views per year

At BMC, research is always in progress.

Learn more biomedcentral.com/submissions 